\title{
Ultracapacitor Storage Enabled Global MPPT for Photovoltaic Central Inverters
}

\author{
Nicolás Müller, Hugues Renaudineau, \\ Freddy Flores-Bahamonde and Samir Kouro \\ Department of Electronic Engineering \\ Universidad Técnica Federico Santa María \\ Valparaíso, Chile 2390123 \\ Email: nicolas.muller@alumnos.usm.cl
}

\author{
Patrick Wheeler \\ Department of Electrical and Electronic Engineering \\ University of Nottingham \\ Nottingham, England NG7 2RD \\ Email: Pat.Wheeler@nottingham.ac.uk
}

\begin{abstract}
In most large-scale grid-tied photovoltaic (PV) plants, central inverter configurations are used, mainly due to higher converter efficiency and lower cost per $k W$. However, compared to other configurations, its Maximum Power Point Tracking (MPPT) efficiency is the lowest since it is the less distributed configuration. Under non-uniform conditions, as mismatch caused by aging and/or partial shading, several local maxima may arise in the PV curve, hence requiring additional actions to maximize the output power of the PV plant. Moreover, tighter grid codes have appeared, requiring for PV systems to limit power fluctuations. This paper presents an alternative to perform Global MPPT (GMPPT) while complying with stiffer grid code limitations. The proposed alternative adds an Energy Storage System (ESS) at inverter level, consisting of an ultracapacitor (UC) bank connected to the DC-link of a PV central inverter through interleaved DC-DC power converters. The proposed configuration is preliminary validated through simulations and tested under extreme conditions. The performance of the system is analyzed and compared to other existing solutions.
\end{abstract}

\section{INTRODUCTION}

Fossil fuels depletion, $\mathrm{CO}_{2}$ emissions, greenhouse effect and government politics have motivated the development and integration of renewable energies into electric networks [1]. Nowadays, $23.7 \%$ of the global electric market is provided by renewable energies [2], [3], being Wind and PV energy conversion systems at the forefront of the renewable integration [3].

Central inverter configurations are the mainstream solution for large scale grid-tied PV plants $(>850 \mathrm{~kW})$ [4], due to its higher conversion efficiency $(>98 \%$ CEC) and lower cost per $k W$, compared to string, multi-string and microinverter configurations. Nevertheless, central inverter configurations show the lowest MPPT efficiency among all configurations, due to its single tracking system for the full PV plant [4].

Under non-uniform conditions, as mismatch due to aging and/or partial shading (clouds, dust, soiling), several local maxima may appear in the PV curve. Figure 1 shows the characteristic curve of the $778 \mathrm{~kW}$ PV plant used in this work, under both Standard Test Conditions (STC) (red) and a partial shading scenario (blue). This partial shading scenario considers $50 \mathrm{PV}$ modules (10 strings, 5 modules per string) having an irradiance of $550 \mathrm{~W} / \mathrm{m}^{2}$, while all other modules of the PV plant operate at $1000 \mathrm{~W} / \mathrm{m}^{2}$ (all modules operate at $25^{\circ} \mathrm{C}$ ); hence generating a PV characteristic having two local maxima.

Classical MPPT algorithms, as Perturb and Observe $(P \& O)$, guarantee to find a maximum, but lack the capability to differentiate between a local and the global maximum. Therefore to generate the maximum available power additional methods are required. An alternative is to scan the PV curve, re-starting the $P \& O$ MPPT strategy near to the global Maximum Power Point (MPP), as proposed in [5]-[8].

The addition of dedicated hardware and two methods for generating the PV curve are proposed in [9]. In [10], an alternative to track the global MPP by modifying the voltage reference is shown. Nevertheless, large power variations are generated by scanning the PV curve; moreover the GMPPT results in energy losses. In [11], distributed PV voltage sensors are added to the PV array, allowing to predict the location of the global MPP in the PV curve. Even though this method may generate possible failures and has a higher cost, it allows to diminish energy losses caused by a blind scan of the PV curve.

A reduction of the voltage scanning range is proposed in [12], hence avoiding open-circuit to short-circuit voltage full scan. A strategy to decrease the power fluctuation steps is presented in [13]. There are several other higher complexity algorithms able to perform the GMPPT. For example the PSO algorithm proposed in [14].

All the above methods experience wide power variations when tracking the global MPP, some grid codes forbid those levels of variations. As an example Puerto Rico has recently set a limitation for PV plants power variation to $10 \%$ per minute of the nominal output power of the PV plant [15]. This restrictions aim to decrease reliability and power quality issues, affecting small/weak grids with high PV penetration, as islands.

The conventional manner to deal with reliability and power quality issues has been to manage power fluctuations (shorter than $10 \mathrm{~min}$ ) through frequency regulation services (mainly through rotating inertia), though in weak grids the alternative has been to rely on the aggregation of geographically disperse PV plants to provide a limited smoothing effect [15], [16]. 


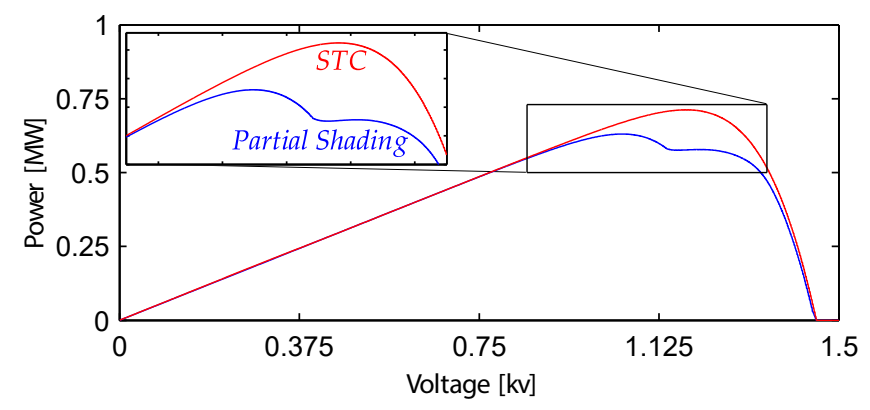

Fig. 1: PV curve under: STC (red) and partial shading (blue)

The addition of an UC-based ESS to regulate output power variations in a central inverter PV plant while performing GMPPT is proposed in [17]. This hybrid system configuration consists of a two-stage power conversion, formed by a DCDC power converter and a DC-AC two level voltage source inverter (2LVSI), connected in parallel to the AC output of the central PV inverter. Both converters, DC-DC and DC-AC, are rated at full power. It is possible to avoid the full power DCAC converter, by merging the ESS at the DC-link of the central inverter PV plant, hence reducing the cost of the ESS (energy storage technology and converter) and decreasing failure rates.

This paper proposes an alternative to perform GMPPT in central inverter PV plants, under non-uniform conditions as partial shading; while keeping output power variation lower than $10 \%$ per minute of the nominal PV plant power. In order to comply with such regulations an electric ESS at inverter level is added; enabling the PV system to store energy during standard operation, and releasing stored energy when performing PV curve scan, hence achieving GMPPT. The ESS is formed by an UC-bank and a single stage DC-DC power converter, connected to the DC-link of the central PV inverter.

The paper is structured in the following way. In section II the description, modeling and parameters of the proposed system are given. The control strategy applied to the system is explained in section III. Simulation results are displayed and analyzed in section IV. Conclusions of the developed work are presented in section $\mathrm{V}$.

\section{SYSTEM DESCRIPTION AND MODELLING}

The proposed configuration is shown in Fig. 2. Where an UC-based ESS is added to the central PV inverter, interconnected through a DC-DC power conversion stage to the DC-link of the PV inverter.

The configuration is formed by two main systems: a PV plant with a 2LVSI as central inverter configuration shown in Fig. 2 (top right), and the ESS formed by an UC-bank and two interleaved Isolated Bidirectional Boost Converters (IBBC), shown in Fig. 2 (bottom left). Both systems are interconnected at the DC-link of the PV inverter.

The 2LVSI is modeled in $d q$ rotating synchronous coordinates in the Laplace domain through equation (1). Where $L_{g}, R_{g}, i_{g d}, i_{g q}, v_{r d}, v_{r q}, v_{g d}, v_{g q}, \omega$ are respectively the filter inductance, filter equivalent resistance, grid current
TABLE I: Configuration parameters.

\begin{tabular}{|c|c|c|}
\hline \multicolumn{3}{|c|}{ PV power plant (under STC conditions) } \\
\hline Maximum power & $P_{p v} m p p$ & $778 \mathrm{~kW}$ \\
\hline Open circuit voltage & $v_{p v o c v}$ & $1460 \mathrm{~V}$ \\
\hline Short circuit current & $i_{p v s c}$ & $710 A$ \\
\hline Maximum power point voltage & $v_{p v} m p p$ & $1184 \mathrm{~V}$ \\
\hline Maximum power point current & $i_{p v m p p}$ & $657 A$ \\
\hline Modules connected in series & $N_{s m}$ & 36 \\
\hline Strings connected in parallel & $N_{p s}$ & 76 \\
\hline \multicolumn{3}{|c|}{$\begin{array}{ll} & \text { 2LVSI \& Grid } \\
\end{array}$} \\
\hline PV 2LVSI DC-link capacitance & $C_{p v}$ & $4400 \mu F$ \\
\hline PV inverter DC-link voltage & $v_{p v}$ & $720-1500 \mathrm{~V}$ \\
\hline Grid voltage & $v_{a c R M S}$ & $440 V_{L L} R M S$ \\
\hline Grid inductance & $L_{g}$ & $0.25 \mathrm{mH}$ \\
\hline Grid frequency & $f_{g}$ & $50 \mathrm{~Hz}$ \\
\hline Switching frequency & $f_{s w}$ & $5 \mathrm{kHz}$ \\
\hline \multicolumn{3}{|c|}{ UC \& IBBC converter } \\
\hline Capacitance & $C_{u c}$ & $27.5 \mathrm{~F}$ \\
\hline Equivalent series resistance & $R_{E S R}$ & $36 m \Omega$ \\
\hline Maximum voltage & $v_{u c \max }$ & $288 \mathrm{~V}$ \\
\hline Maximum current & $i_{u c \max }$ & $1900 A$ \\
\hline IBBC inductance & $L_{b b}$ & $0.1 \mathrm{mH}$ \\
\hline IBBC inductance resistance & $R_{L b b}$ & $0.01 \Omega$ \\
\hline Isolating transformer ratio & $n_{1}: n_{2}$ & $1: 2$ \\
\hline Switching frequency & $f_{b b}$ & $50 \mathrm{kHz}$ \\
\hline Sampling period & $T_{s}$ & $5 \mu \mathrm{s}$ \\
\hline
\end{tabular}

in d-axis, grid current in q-axis, converter voltage in d-axis, converter voltage in q-axis, grid voltage in d-axis, grid voltage in q-axis and the electric angular frequency.

$$
\left[\begin{array}{c}
i_{g d} \\
i_{g q}
\end{array}\right]=\frac{1}{L_{g} s+R_{g}}\left(\left[\begin{array}{c}
v_{r d} \\
v_{r q}
\end{array}\right]+\left[\begin{array}{c}
L_{g} \omega i_{g q}-v_{g d} \\
-L_{g} \omega i_{g d}-v_{g q}
\end{array}\right]\right)
$$

The model of the IBBC in Laplace domain is given by equation (2). Where $L_{b b}, R_{L b b}, i_{L b b x}, v_{u c}, v_{p v}, m, n_{1}, n_{2}$ are respectively the inductance, resistance of the inductance, current through the inductance $x(x \in\{1,2\})$, voltage of the UC-bank, voltage of the DC-link of the 2LVSI, duty cycle, number of turns in the primary of the transformer and number of turns in the secondary of the transformer.

$$
i_{L b b x}=\frac{1}{L_{b b} \cdot s+R_{L b b}}\left(v_{u c}-m \cdot v_{p v} \cdot \frac{n_{1}}{n_{2}}\right)
$$

The IBBC manages the power flow between the UC-bank $\left(C_{u c}\right)$ and the DC-link $\left(C_{p v}\right)$. In boosting operation (when the UC-bank delivers power to the DC-link), only the primaryside semiconductors $\left(S_{a}\right.$ and $\left.S_{b}\right)$ are switched, keeping the secondary-side semiconductors $\left(S_{c 1}, S_{c 2}, S_{d 1}\right.$ and $\left.S_{d 2}\right)$ opened hence operating as a full diode bridge. In buck operation (when the power flows from the DC-link to the UC-bank), the secondary-side semiconductors are switched $\left(S_{c 1}, S_{c 2}, S_{d 1}\right.$ and $\left.S_{d 2}\right)$, and the primary-side semiconductors $\left(S_{a}\right.$ and $\left.S_{b}\right)$ are kept opened operating as a full diode bridge.

The UC-bank model considers a RC equivalent circuit [18], formed by the UC-bank capacitance $\left(C_{u c}\right)$ and the equivalent series resistance $\left(R_{E S R}\right)$.

Simulation was performed in the software PLECS $\circledR$. Table I shows the parameter used to simulate the proposed configuration. Canadian Solar CS6X-325P-FG PV modules 


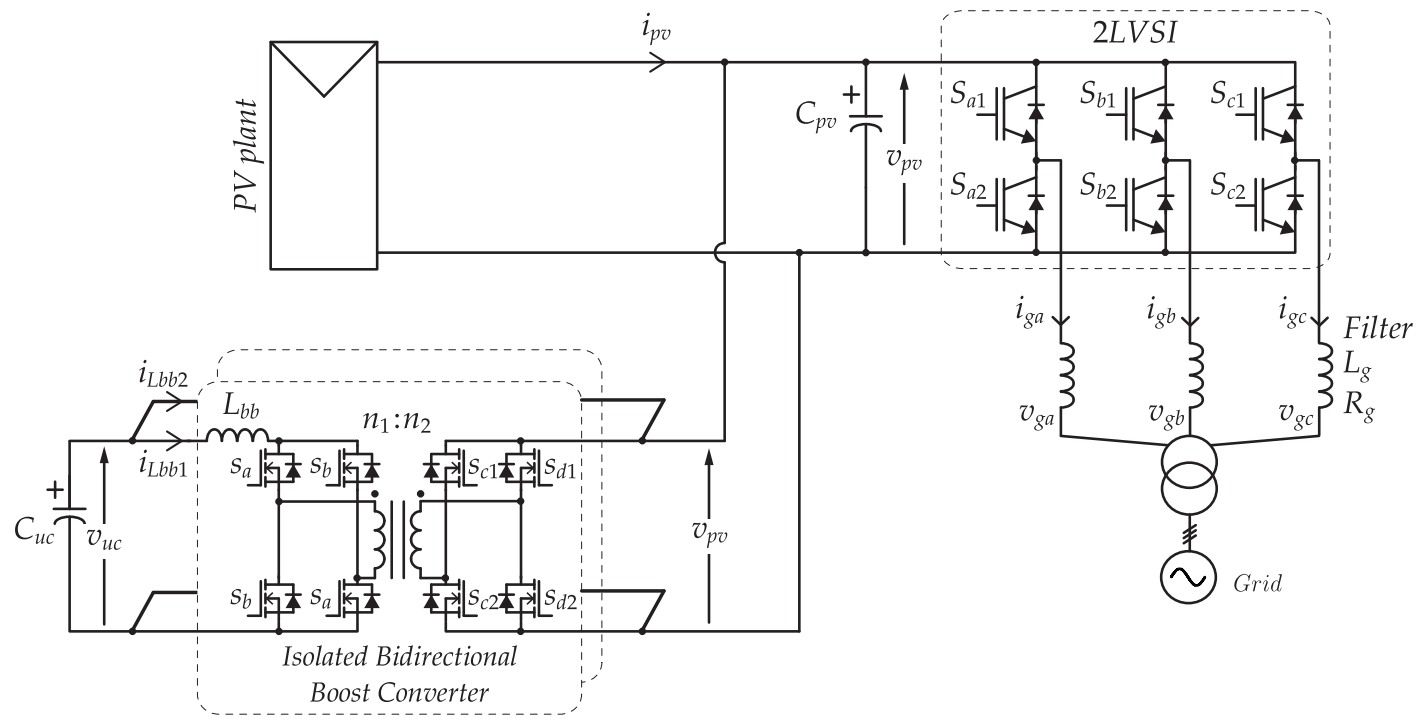

Fig. 2: Full proposed configuration formed by a PV plant with central inverter configuration (2LVSI), a UC-bank and its interleaved IBBC.

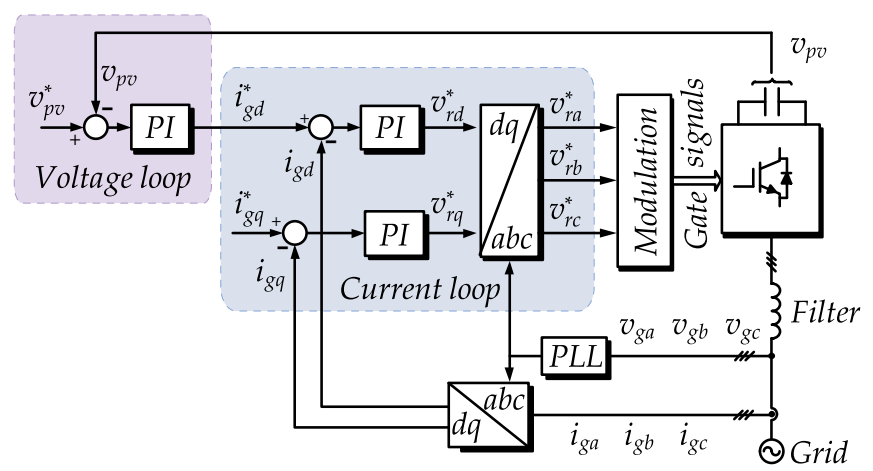

Fig. 3: PV plant 2LVSI control scheme.

(1.5 $k V$ isolation), GE Pro-Solar PSC-800 MV-L-QC central solar inverter and Maxwell UC module BMOD0165 P048 BXX were considered to size the full system [19]-[21]

\section{CONTROL}

Voltage Oriented Control (VOC) is chosen as the strategy to control the DC-link voltage $\left(v_{p v}\right)$ and regulate the currents injected to the grid $\left(i_{g a}, i_{g b}\right.$ and $\left.i_{g c}\right)$ through the 2LVSI, a diagram of this control strategy is shown in Fig. 3. Where $v_{r a}^{*}, v_{r b}^{*}$ and $v_{r c}^{*}$ correspond to the converter phase voltages, $v_{g a}, v_{g b}$ and $v_{g c}$ to the phase voltages in the grid, $i_{g a}, i_{g b}$ and $i_{g c}$ to phase currents injected to the grid.

The full system has two operating modes, which provide the DC-link voltage loop reference $\left(v_{p v}^{*}\right)$ and the UC-power reference $\left(P_{u c}^{*}\right)$. Regarding the DC-link voltage loop reference, the first operating mode is conventional MPPT, through $P \& O$; and the second operating mode corresponds to the PV curve scanning, through voltage swipe.

Figure 4 shows the PV plant initially operating in $P \& O$ mode, passing through Scanning mode, and returning to $P \& O$

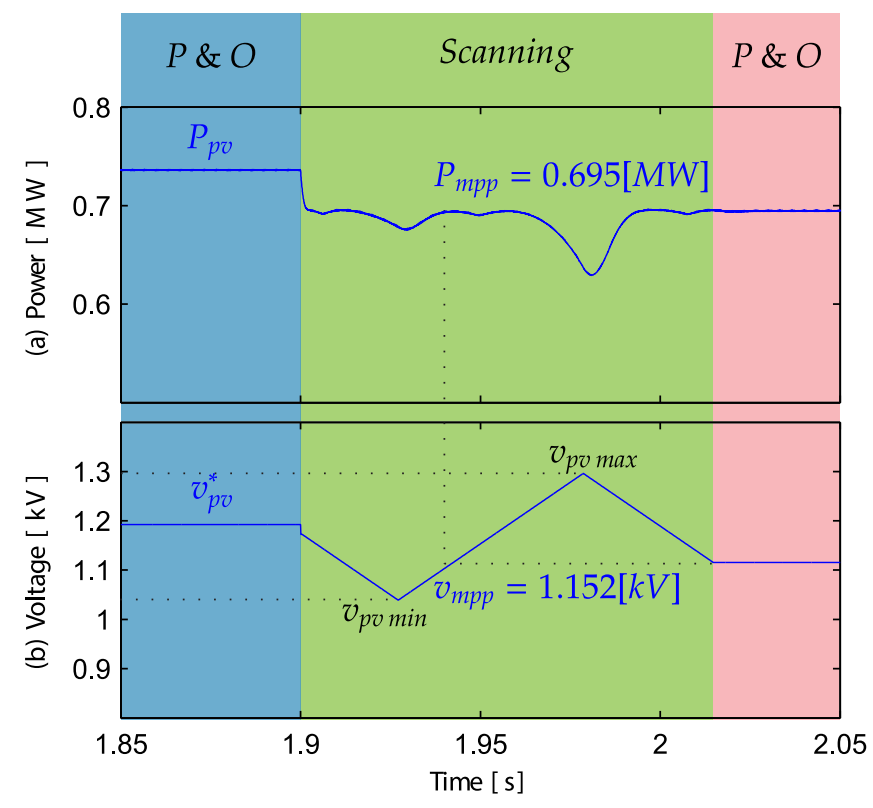

Fig. 4: PV plant dynamics during $P \& O$ and PV curve scanning: a) PV plant output power $\left(P_{p v}\right)$, b) DC-link voltage reference $\left(v_{p v}^{*}\right)$.

mode. When the system is performing Scanning, the PV plant voltage reference $v_{p v}^{*}$ is moved to $v_{p v \text { min }}$, and then swapped to $v_{p v \max }$. During the swapping, from $v_{p v \min }$ to $v_{p v \max }$, the global MPP $\left(P_{m p p}\right)$ is found, and the voltage generating the MPP $\left(v_{m p p}\right)$ is set as the new reference $\left(v_{p v}^{*}=v_{m p p}\right)$. Once the DC-link has reached the new voltage reference, the system is returned to $P \& O$. During Scanning mode the voltage reference rate is limited, in order to limit the power requirement for the ESS.

The minimum and maximum voltages to perform the voltage scan are $v_{p v \min _{k}}=\max \left(P_{m p p_{k-1}} / i_{p v s c_{s t c}}, v_{d c \min }\right)$ 


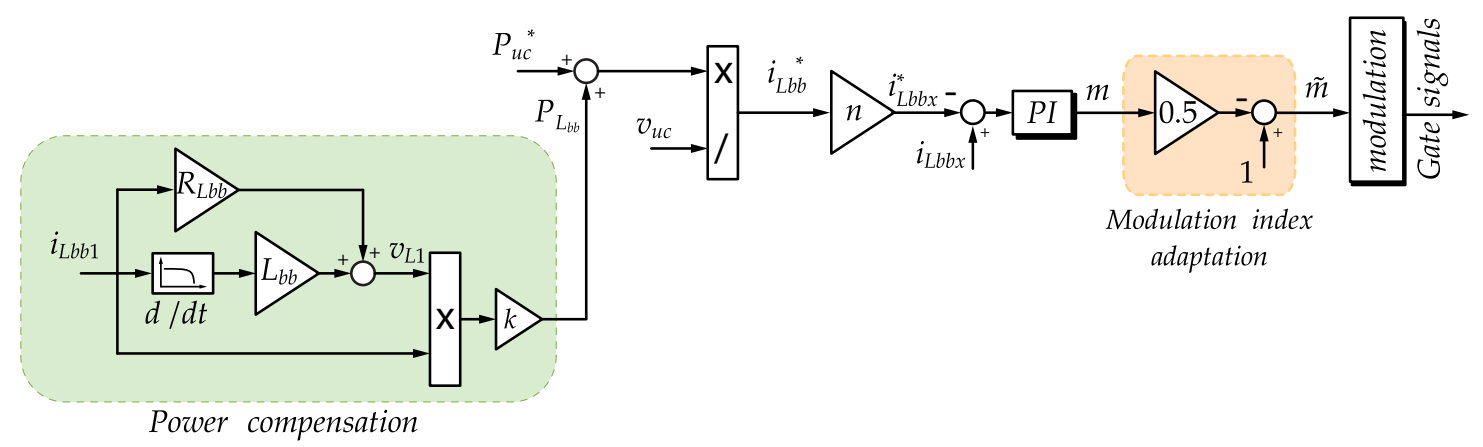

Fig. 5: IBBC control scheme.

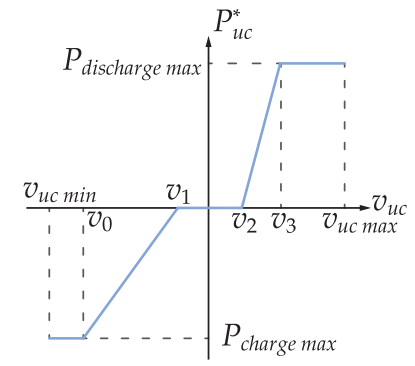

Fig. 6: UC-bank charging strategy.

and $v_{p v \max }=0.9 \cdot v_{p v o c v}$, where $P_{m p p_{k-1}}, i_{p v s c_{s t c}}, v_{d c \min }$ and $v_{p v o c v}$ correspond to the MPP in time $k-1$, the PV plant short-circuit current under STC, minimum DC-link voltage to allow controlability of the grid side converter and the open-circuit voltage in the terminals of the PV plant under STC, respectively [12]. It must be noticed that the lower limit $\left(v_{p v \min }\right)$ is dynamic, while the upper limit $\left(v_{p v \max }\right)$ is constant.

The control scheme to manage the power flow from/towards the UC-bank is shown in Fig. 5. The UC-bank power reference $\left(P_{u c}^{*}\right)$ depends on the operating mode of the MPPT, namely Scanning or $P \& O$. When Scanning, the UC-bank power reference $\left(P_{u c}^{*}\right)$ is given by $P_{u c}^{*}=\bar{P}_{p v}-P_{p v}$, where $\bar{P}_{p v}$ and $P_{p v}$ are respectively the moving average of the power generated by the PV plant (10 sample moving average) and the instantaneous power generated by the PV plant. On the other hand when performing $P \& O$, hence managing the charging of the UC-bank, the UC-bank power reference $\left(P_{u c}^{*}\right)$ is given by the curve shown in Fig. 6 .

The power in the inductance of the IBBCs $\left(P_{L_{b b}}\right)$ is estimated by the Power compensation block, where $v_{L 1}$ corresponds to the estimated voltage in the inductance. The sum of $P_{u c}^{*}$ and $P_{L_{b b}}$ is divided by the UC-bank voltage $v_{u c}$ generating the current reference for the $\operatorname{IBBC}\left(i_{L b b}^{*}\right)$. Afterwards the current reference is scaled down to even current flow through each interleaved IBBC (since there are $k=2$ interleaved IBBCs, $n$ is chosen as $1 / k=1 / 2$ ). The current control loop generates the modulation index $m$ for each IBBC. In order to generate a symmetric signal for the transformer the modulation index must be adapted, generating $\tilde{m}$. This new
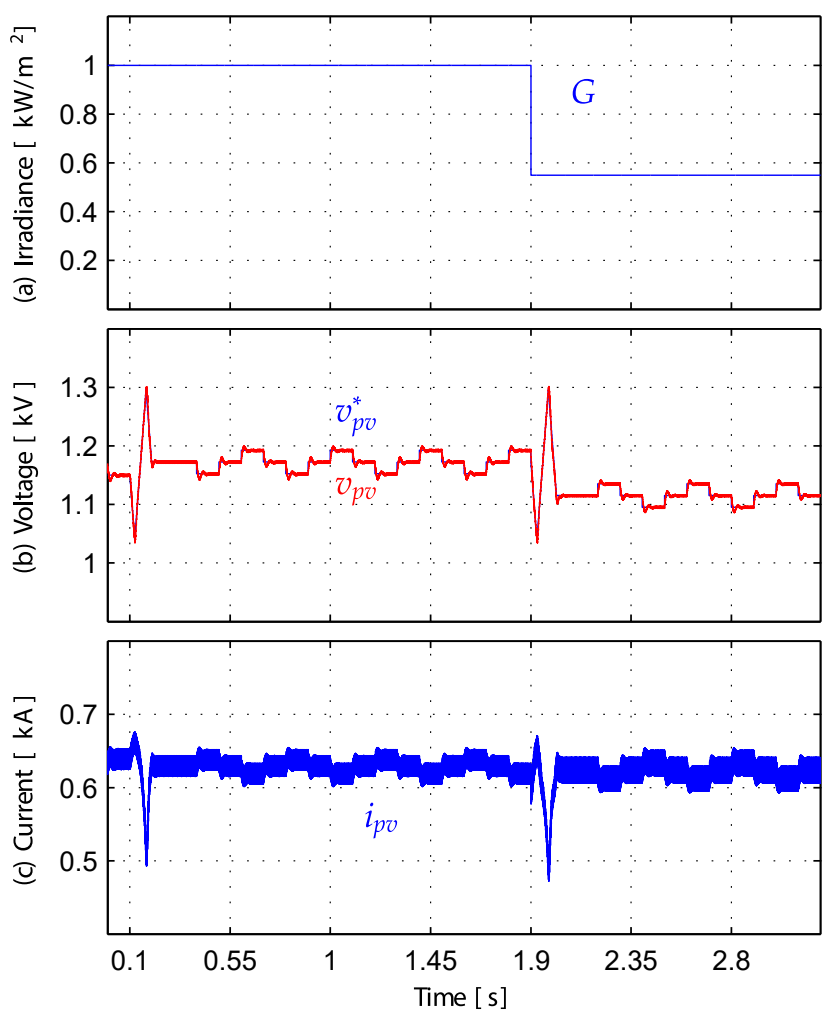

Fig. 7: PV plant simulation results: a) Solar irradiance $(G)$, b) PV plant voltage $\left(v_{p v}\right)$ and reference $\left(v_{p v}^{*}\right)$ and c) PV plant output current $\left(i_{p v}\right)$.

modulation index is fed to the modulation block.

\section{Simulation Results}

In order to validate the proposed strategy a step down in solar irradiance from $1000 \mathrm{~W} / \mathrm{m}^{2}$ to $550 \mathrm{~W} / \mathrm{m}^{2}$ is applied to $50 \mathrm{PV}$ modules of the PV plant (10 strings, 5 modules per string, full PV plant has 2,736 modules) at $1.9 \mathrm{~s}$. As stated before, Fig. 1 shows the PV curve operating under STC (before $1.9 \mathrm{~s}$ ) and the system operating under partial shading scenario (after $1.9 \mathrm{~s}$ ).

Two voltage scans are performed to find the global MPP, an initial voltage scan at $t=0.1 \mathrm{~s}$ is run to find the initial global MPP, and a second voltage scan is triggered by the step 

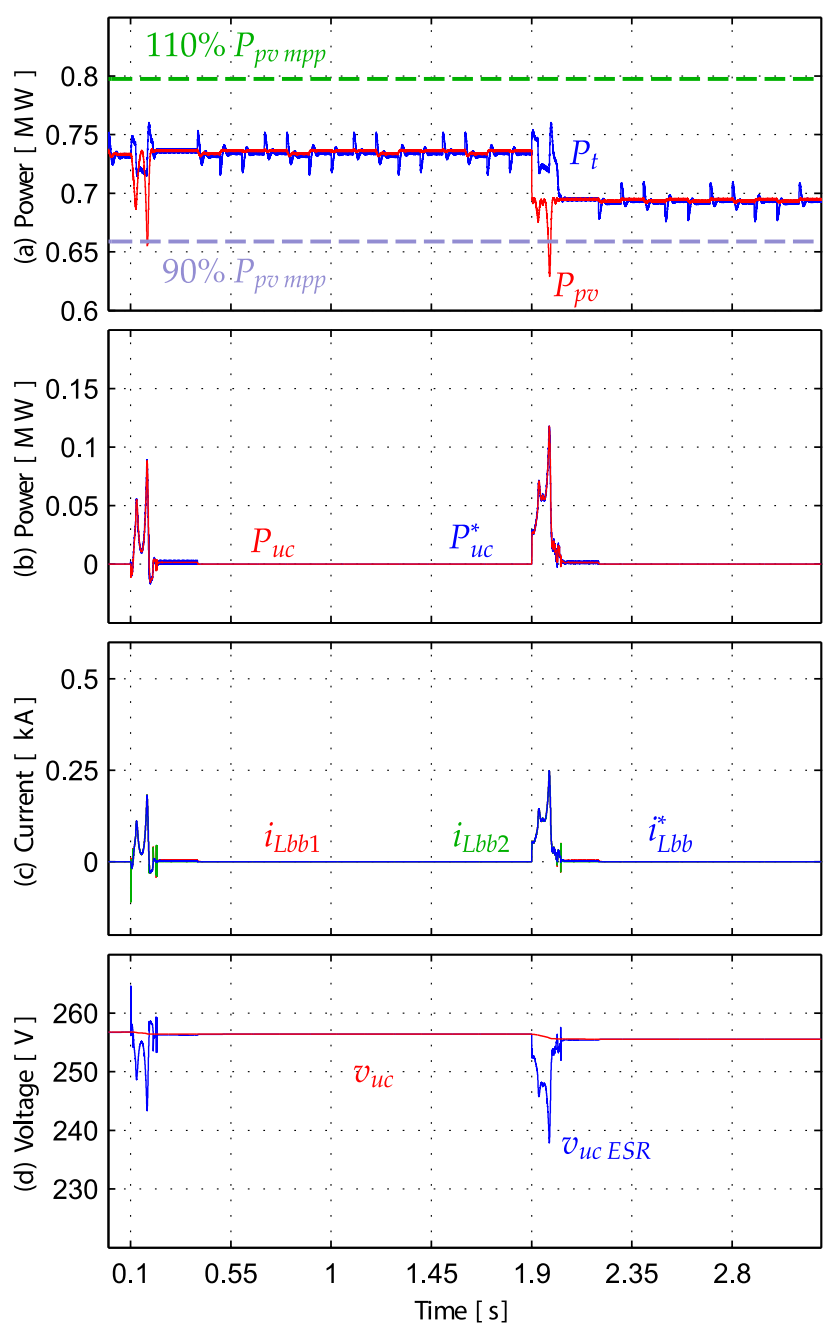

Fig. 8: IBBC simulation results: a) Full system output power $\left(P_{t}\right)$, PV plant output power $\left(P_{p v}\right)$, maximum power variation per minute $\left(110 \% P_{p v} m p p\right)$ and minimum power variation per minute $\left(90 \% P_{p v} m p p\right)$, b) UC output power $\left(P_{u c}\right)$ and reference $\left(P_{u c}^{*}\right)$, c) IBBC inductance currents $\left(i_{L B B 1}\right.$ and $\left.i_{L B B 2}\right)$ and reference $\left(i_{L B B}^{*}\right)$ and d) UC bank terminal voltage $\left(v_{u c E S R}\right)$ and estimated $\mathrm{UC}$ bank voltage without equivalent series resistance $\left(v_{u c}\right)$.

down in PV output power at $1.9 \mathrm{~s}$. Figure 7a shows the solar irradiance. The DC-link voltage $\left(v_{p v}\right)$ and its reference $\left(v_{p v}^{*}\right)$ are shown in Fig. 7b, during normal operation classic $P \& O$ is performed, when scanning a voltage swap is performed, as seen at 0.1 and $1.9 \mathrm{~s}$. Both modes, $P \& O$ and Scanning, are reflected in the PV plant output current $\left(i_{p v}\right)$, as seen in Fig. 7c.

Power injected to the grid must not exceed variations greater than $10 \%$ per minute of the nominal output power of the PV plant. In order to comply this restriction the UC-bank provides power during the voltage scan, keeping the power injected to the grid within grid code limits. Fig 8a shows the power injected to the grid $\left(P_{t}\right)$, the power provided by the PV plant $\left(P_{p v}\right)$ and in dashed lines the upper and lower limits to keep power variations within $10 \%$ per minute of the nominal PV plant output power. It must be noticed that the decrease in

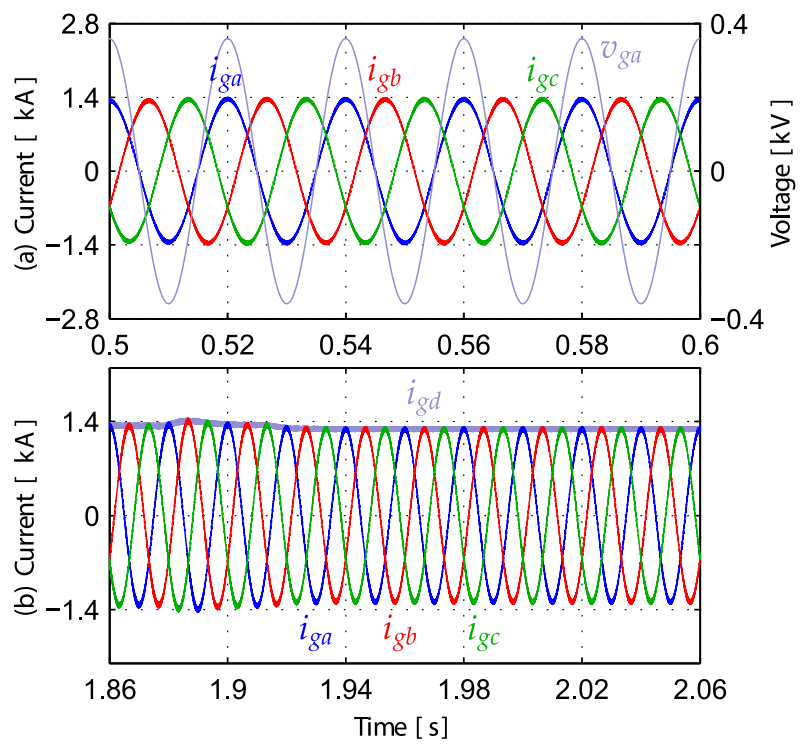

Fig. 9: Grid currents and phase voltage: a) Line currents $\left(i_{g a}, i_{g b}\right.$ and $\left.i_{g c}\right)$ and grid phase voltage $\left(v_{g a}\right)$ during steady state, b) Line currents $\left(i_{g a}, i_{g b}\right.$ and $\left.i_{g c}\right)$ and d-axis grid current $\left(i_{g d}\right)$ during dynamic performance.

power injected to the grid after $1.9 \mathrm{~s}$ is caused by the step down in solar irradiance. The small peaks in $P_{t}$ during $P \& O$ are required to generate the DC-link voltage steps and are caused by the VOC scheme regulating the DC-link voltage. Without the ESS the GMPPT through the proposed PV curve voltage scan, will generate power variations greater than those allowed by this stiffer grid code, as seen in the $P_{p v}$. Fig $8 \mathrm{~b}$ shows the power injected from the UC-bank to the DC-link, where both voltage scans generate the power injections at 0.1 and $1.9 \mathrm{~s}$. Both currents through the inductance of the interleaved IBBC $\left(i_{L b b 1}\right.$ and $\left.i_{L b b 2}\right)$ and its reference $\left(i_{L b b}^{*}\right)$ are shown in Fig. 8c. Figure 8d show the UC-bank terminal voltage $\left(v_{u c} E S R\right)$ and the estimated open circuit voltage of the UC-bank $\left(v_{u c}\right)$; the voltage drop caused by the equivalent series resistance is estimated as the product of the current through both IBBC inductors by the nominal equivalent series resistance. After Scanning has been performed and the MPP tracking strategy has returned to $P \& O$, the charging of the UC-bank takes place according to the previously mentioned strategy.

Grid currents $\left(i_{g a}, i_{g b}\right.$ and $\left.i_{g c}\right)$ and grid phase voltage $a$ $\left(v_{g a}\right)$ under steady state operation are shown in Fig. 9a, where the synchronicity between $i_{g a}$ and $v_{g a}$ proofs the operation near unitary power factor. The dynamic performance of grid $\left(i_{g a}, i_{g b}\right.$ and $\left.i_{g c}\right)$ and rotational d-axis $\left(i_{g d}\right)$ currents, caused by the PV curve voltage scan, are shown in Fig. 9b. Where the decrease in amplitude of grid currents (from $1.9 \mathrm{~s}$ ) reflects the new (lower) MPP of the PV curve, generated by the partial shading scenario.

\section{CONClusion}

This paper presents an alternative to perform GMPPT on large-scale PV plants, while keeping power variation limited to a maximum of $10 \%$ per minute of the nominal output power of 
the PV plant. Compared to other voltage swiping techniques, this solution complies with stiffer grid code limitations for grids with high penetration levels of renewables, as Puerto Rico.

The current work validates through simulation the configuration and proposed control strategy.

The proposed hybridization of the PV plant with the ESS at DC side (inverter level), compared to hybridization of the ESS at the AC side (grid level), allows to avoid the usage of an additional full power DC-AC converter and its grid filter, hence decreasing the number of required sensors. Therefore allowing an increase of the reliability and efficiency of the system, and decreasing losses, failure rates and price.

\section{ACKNOWLEDGMENT}

The authors gratefully acknowledge the financial support by the Advanced Center for Electrical and Electronic Engineering (AC3E) CONICYT/BASAL/FB0008, by SERC Chile CONICYT/FONDAP/15110019, by CONICYT-PCHA/Doctorado Nacional/2014-21141092 and by PAI/Concurso Nacional de Apoyo al Retorno de Investigadores/as desde el Extranjero, Convocatoria 2014, F82140010.

\section{REFERENCES}

[1] I. E. Commission et al., Grid Integration of Large-capacity Renewable Energy Sources and Use of Large-capacity Electrical Energy Storage: White Paper; October 2012. International Electrotechnical Commission, 2012.

[2] REN21, Renewables 2016 Global Status Report www.ren21.net. REN21, 2016.

[3] REN21, The First Decade 2004-2014 www.ren21.net. REN21, 2016.

[4] S. Kouro, J. Leon, D. Vinnikov, and L. Franquelo, "Grid-connected photovoltaic systems: An overview of recent research and emerging pv converter technology," IEEE Ind. Electron. Mag., vol. 9, no. 1, pp. 4761, March 2015.

[5] H. Renaudineau, A. Houari, J.-P. Martin, S. Pierfederici, F. MeibodyTabar, and B. Gerardin, "A new approach in tracking maximum power under partially shaded conditions with consideration of converter losses," Solar Energy, vol. 85, pp. 2580-2588, 2011.

[6] Q. Duan, J. Leng, P. Duan, B. Hu, and M. Mao, "An improved variable step po and global scanning mppt method for pv systems under partial shading condition," in Intelligent Human-Machine Systems and Cybernetics (IHMSC), 2015 7th International Conference on, vol. 1, Aug 2015, pp. 382-386.

[7] B. N. Alajmi, K. H. Ahmed, S. J. Finney, and B. W. Williams, "A maximum power point tracking technique for partially shaded photovoltaic systems in microgrids," IEEE Tran. on Ind. Electron., vol. 60, no. 4, pp. 1596-1606, April 2013.

[8] K. Itako, "Pcs with scanning-type mppt control for industrial gridconnected pv power generation system," in 2014 International Power Electronics Conference (IPEC-Hiroshima 2014 - ECCE ASIA), May 2014, pp. 3244-3248.

[9] R. Kot, S. Stynski, and M. Malinowski, "Simple scanning methods for a global-mpp determination in a pv string," in Selected Problems of Electrical Engineering and Electronics (WZEE), 2015, Sept 2015.

[10] H. Renaudineau, F. Donatantonio, J. Fontchastagner, G. Petrone, G. Spagnuolo, J.-P. Martin, and S. Pierfederici, "A pso-based global mppt technique for distributed pv power generation," IEEE Trans. Ind. Electron., vol. 62, no. 2, pp. 1047-1058, Feb 2015.

[11] K. Chen, S. Tian, Y. Cheng, and L. Bai, "An improved mppt controller for photovoltaic system under partial shading condition," IEEE Tran. on Sust. Energy, vol. 5, no. 3, pp. 978-985, July 2014.

[12] M. Boztepe, F. Guinjoan, G. Velasco-Quesada, S. Silvestre, A. Chouder, and E. Karatepe, "Global mppt scheme for photovoltaic string inverters based on restricted voltage window search algorithm," IEEE Tran. on Ind. Electron., vol. 61, no. 7, pp. 3302-3312, July 2014.
[13] E. Koutroulis and F. Blaabjerg, "A new technique for tracking the global maximum power point of pv arrays operating under partial-shading conditions," IEEE Journal of Photovoltaics, vol. 2, no. 2, pp. 184-190, April 2012.

[14] K. Ishaque and Z. Salam, "A deterministic particle swarm optimization maximum power point tracker for photovoltaic system under partial shading condition," IEEE Trans. on Ind. Electron., vol. 60, no. 8, pp. 3195-3206, Aug 2013.

[15] J. Marcos, O. Storkl, L. Marroyo, M. Garcia, and E. Lorenzo, "Storage requirements for pv power ramp-rate control," Solar Energy, vol. 99, pp. $28-35,2014$.

[16] National Renewable Energy Laboratory (NREL), Review of PREPA Technical Requirements for Interconnecting Wind and Solar Generation www.nrel.gov/docs/fy14osti/57089.pdf. NREL, 2013.

[17] N. Müller, S. Kouro, H. Renaudineau, and P. Wheeler, "Energy storage system for global maximum power point tracking on central inverter pv plants," in Power Electronics Conference (SPEC), IEEE Annual Southern. IEEE, 2016, pp. 1-5.

[18] L. Shi and M. Crow, "Comparison of ultracapacitor electric circuit models," in Power and Energy Society General Meeting-Conversion and Delivery of Electrical Energy in the 21st Century, 2008 IEEE. IEEE, 2008, pp. 1-6.

[19] Canadian Solar, Canadian Solar, solar panels, CS6X-P-FG www.canadiansolar.com. Canadian Solar, 2016.

[20] G. power conversion, GE power conversion, ProSolar Central Solar Inverter www.gepowerconversion.com. General Electric Power Conversion, 2012.

[21] Maxwell, Products, Ultracapacitors www.maxwell.com. Maxwell, 2015. 